INTERNATIONAL DESIGN CONFERENCE - DESIGN 2018

https://doi.org/10.21278/idc.2018.0361

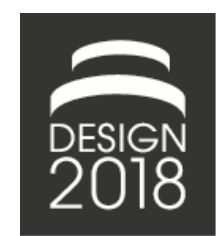

\title{
LESSONS LEARNT IN DESIGNING TRANSPORTATION SOLUTIONS FOR ELDERLY PEOPLE FOLLOWING A PARTICIPATORY APPROACH
}

\author{
A. Wallisch, L. Maccioni, L. Trautmann, E. Ostermeyer, Y. Borgianni and J. C. Borg
}

\begin{abstract}
Aging societies have an extended need for transportation solutions that enhance elderly's independence. However, the solutions needed are as manifold as the elderly's lifestyles are. This study uses Usercentred Design principles as a structuring tool to manage this complexity of requirements. By not just focusing on specific functionalities but also reflecting product life cycle and usage context, new types of requirements can be revealed. Through a case study, this article shows how a participatory design approach can lead to integrated solutions that better fit the user's needs.
\end{abstract}

Keywords: integrated product development, requirements management, human centred design, co-design, teamwork

\section{Introduction}

Today's requirements on products in their whole life cycle has become increasingly complex. Developing and designing products is characterized by the ability to repeatedly employ problem solving, creativity and decision-making in an efficient manner to reach an adequate product definition. In this sense, a formalism that defines how steps are to be carried out and/or how working results can be documented is needed. In addition, different professional perspectives have to be integrated in the decisions to be made in different design phases (Andreasen and Hein, 1987; Vajna, 2014). Decisions have their consequences. If these turn out to be disadvantageous retrospectively, it might be hard and expensive to correct them. To ensure that the development really does meet user needs, it is important to grasp design not only in its functional aspect of the designed object but also in its emotional and social aspects that ultimately control the human behaviour and, thus, affect purchasing decisions on products.

The aim of the paper at hand is to outline how different methods of user-centred design research can raise awareness to non-functional requirements and improve design solutions for sensitive target groups. A case study will be presented, carried out by a multidisciplinary team of postgraduate students working on mobility solutions for the elder population during an International Summer School. Within a period of four months to perform the case study, participants experienced a practical product development scenario. This paper reports the logical flow the team has followed and shows how social aspects can affect design in order to provide guidance in approaching relevant issues.

In the next section, the team composition, the development task and first implications are reported for carrying out the task effectively. This is followed by some literature indications that support the choice of embarking in human-centred design in section three. In the fourth section, the design strategy chosen by the project team is described by depicting different ways to explore user 
requirements. In the fifth section, the solution finding process and the solution to address these requirements are presented. Eventually, a conclusion and some reflections on the project work will be given.

\section{Development task}

As previously mentioned, product and process technology is rapidly evolving and competition is becoming more and more globally based. This dynamic and challenging environment might benefit from the implementation of integrated product development concepts to reduce development cycle time and improve product quality and value. The aim of the International Summer School on Integrated Design (ipdISS, 2017 edition) was to provide a platform through which postgraduates working can sharpen their understanding of current and emerging research issues in this interdisciplinary field. The project team presenting its work in this paper consist of four postgraduate students from different countries and disciplines: a sociologist, a product designer, an engineering designer and a manufacturing designer. In a first week, all participants were trained in the overall IPD methodology and relevant methods. At the end of this week, this project team was assigned a development task, which was to be solved independently in a four-month practical phase. Regular Skype meetings were scheduled already at the beginning of the project period, in which new subtasks were defined and the outcomes of the previous ones were assessed. The task was formulated as follows:

"Development of a mechanical transportation solution for the elderly, which should be easy to store"

This task reflects a major social trend: modern societies are getting older and older, and the growing population group is changing in their product requirements and needs (United Nations, 2013). Activities like shopping, consulting doctors or simply visiting neighbours or friends are described as increasingly strenuous (Seidel et al., 2011). At an increased age, rapid changes in the environment lead to fear uncertainty in dealing with previously well-known situations. As a result, such activities are often abandoned consequently (Backes and Clemens, 1998; Clemens, 2004; Limbourg and Matern, 2009). Cognitive, sensory and motoric limitations do no longer allow some activities as well. This results in growing deficits regarding other competences. On the one hand, restrictions in mobility provokes a decrease in social contacts. On the other hand, the loss of independence or at least restrictions in physical and psychological well-being are experienced (Mollenkopf and Flaschenträger, 2001).

Therefore, the aim of the project was to develop a solution that supports everyday activities like the ones mentioned above and maintains the motoric competences of elderly people through training during the usage. Furthermore, safety in use should be emphasized as a main argument for product usage, which enhances life quality. Few boundary conditions were given: elderly people in urban regions should be addressed, which is firstly linked to short distances that have to be covered and secondly to a limited storage capacity, because most of these people live in small rented apartments with limited basement capacity. The solution should effectively enable this target group to stay healthy, independent, safe and socially connected.

\section{Design indications when designing for the elderly}

Product development works according to the principle of finality: the product's effect that the engineering designer anticipates is to assist the user in coping with her/his everyday life, to bring her/him pleasure or to support her/him in acting in specific action situations. The moment, the human being becomes the valuation standard, it is necessary to describe her/him in her/his role as user, in order to recognize her/his desires and needs and to align the development activities on them. To effectively address values and benefits of special products, the design of technology for the elderly can benefit from being based on a proper understanding of the population's needs and expectations (Paetzold and Wartzack, 2012). User-centred design captures the concept of involving users in the design process of interactive products by understanding their needs and various contexts in order to deduce the design requirements from it (Lee et al., 2013). It aims to design and develop a product based on the needs and interests of its users, so that they will find it useful and usable. According to DIN ISO (2010), this 
requires the user to be actively involved in the design process. At the same time, the value in use goes far beyond mere practical suitability and encompasses the entire user experience the product use offers (Hassenzahl, 2008).

However, even a user-centred design does not necessarily take into account the holistic level of user experience. If the user is only involved at the end of a development step and for evaluation purposes, she/he ultimately tests only usability. This is a main criticism of existing products for the elderly: The experiential and knowledge gaps between designers and users are even larger when products are developed for older people, who have limited roles in design and are often reduced to testers in the late design process (Eisma et al., 2004; Essén and Östlund, 2011). As a result, existing technologies targeted for the older population have often been designed based on an insufficient understanding or stereotypes and not been adopted or used with enthusiasm (Walter et al., 2015). Therefore, it is discussed that elderly's needs and expectations are not properly assessed in design practice (NiemeläNyrhinen, 2007). The main goal of product development is to examine how products in general and technical systems in particular can be adapted in such a way that the elderly may operate them safely and easily (Biermann and Weißmantel, 2003). It therefore focuses on the mental and physical conditions of the elderly. However, this is just one side of the coin: even the best-developed technical solution will not be used until the elderly find it valuable and useful. The elderly are not fundamentally adverse to technology, but have simply consolidated their everyday routines over a long period of time (Birken et al., 2016). They may therefore react with suspicion to the prospect of change in their routines because change primarily means the altering of their usual rhythm and the perceived restriction of their own sovereignty. It is, however, important for the well-being and independence of the elderly that they maintain their own capabilities for as long as possible. Additionally, by the time one reaches a certain age, each individual has already developed their own solutions for specific problem situations due to their still existing competencies, such that they no longer perceive them as such (Birken et al., 2016). Therefore, product development must address the concrete everyday practices of users, too.

Users, who have special needs compared to average consumers, are usually excluded from using many products, services or systems. Since the design team would like to empower elderly people to enhance their mobility by the use of technical products, it must take into consideration their special needs. Nevertheless, this does not necessarily mean that one should create products only suitable for those. In contrast, the overall aim should be to ensure the comfort of the usage of product for the widest possible consumer group (Connell et al., 1997, Clarkson et al., 2013). This design philosophy is named Universal or Inclusive design (also called "Design for All"). It aims to avoid stigmatization of user groups with different needs than the average by creating solutions that both meet the needs of average and special user layers (Preiser and Smith, 2011). While working on the design task, both components have to be taken into account: the requirements of the elderly for a transport solution that attract other groups of people as well.

Within the definition of design requirements, the focus can broadly be on the user or on the product, as highlighted in the different models surveyed by Pucillo et al. (2016). When the focus is directed towards users, the definition of requirements is more abstract and the process lends itself to a wider exploration of the design space, as conceptual solutions can be more differentiated (Rieuf et al., 2015). This is enabled by design methods of user-centred design and stresses the relevance of user experience in participatory design initiatives (Wilkinson and De Angeli, 2014). User participations vary in terms of type, degree, content, extent, and formality. The user's impact can contribute to different roles they can take over in the design process (Damodaran, 1996). By not just focusing on specific functionalities but also reflecting product life cycle and usage context, new types of requirements can be revealed. In the following, it will be illustrated how a participatory design approach can lead to integrated solutions that better fit the user's needs compared to those just focusing on physical functionalities.

\section{User integration in product design practices}

As a theoretical framework for integrating knowledge and expectations of the users into product development processes, user integration causes a densification of product-relevant users and their 
usage context (Ottosson and Sterten, 2014). The aim to do so is to ensure the identification and prioritization of the use cases and product requirements from the user's perspective. This can be done in a more passive way, for example in the case of a standardized survey, or in an active way, for example if the user directly takes part in the development team (Barki and Hartwick, 1989). The nature of the integration depends on its objectives significantly. This is not only a question of the extent to which the user's life and action situation is depicted, but it also relates to the results to be expected. In the followings, the three different approaches of user integration in design, which the design team pursued during the concept development phase, are presented: a predominantly designer-driven brainstorming to structure the information that the summer school has provided, the reflection of the perspective of the elderly in a more user-driven concept development and, eventually, a participatory solution search.

\subsection{Designer-driven concept development}

As a starting point of the project, the design team agreed on that, on a high level of abstraction, the functionality of the solution to be developed is to simplify both, the movement of an elderly person outside and carrying things. During an intensive brainstorming phase, the team decided that the solution does not have to be similar to a car, because this might be overly complex, probably too expensive for the reference customers and does not help with training physical abilities. The artefact might be more like a common bicycle with particular improvements because standard bicycles might require skills that elderly people no longer have. At this point, it is worth noting that the design space to be potentially explored for a means of transportation could be larger. However, the design team, which was also challenged by time constraints and an interdisciplinary knowledge basis, needed a starting point for communicating with potential users about their requirements for a transportation system. It was supposed and defined that a bicycle could represent the best reference, which should be further developed according to the user needs. Within the design team, some functional requirements were known as typical for senior bikes:

- stability,

- manual power assistance,

- ergonomic comfort,

- easy to move,

- easy to understand,

- easy to store.

Different usage scenarios were conceptualized in order to derive first solution concepts (see Table 1, in which target requirements and development directions are depicted). The usage situations as well as the user-specific contexts are so heterogeneous that the explanatory power of this reduction at the same time has also to be called into question. In practice, the design process is seriously complicated by the fact that many products are actually used by a wide variety of users, who have different goals and use the product in various contexts. Due to the heterogeneity within the users' group, it seems important to validate the user needs and requirements during the overall development process. Not only the analysis and description of the user as a starting point is necessary: the translation of the rather soft wishes of the users into concrete product functions and parameters needs to be validated and verified continuously.

Meanwhile, a benchmark research revealed that many options addressing the special ergonomic needs of elderly people are already available on the market. The search results revealed many different tricycles, senior bicycles, four-wheel variants, various concepts of different frames and wheels and even cargo bikes. On the other hand, with under two percent, the real market share was strikingly low (Mottschall, 2012). In order to understand this discrepancy, for a more detailed requirements specification not only the user's needs, but also the barriers to use and the reasons for non-use should be examined. 
Table 1. User-usage scenarios as formulated by the design team

\begin{tabular}{|c|c|}
\hline Target users, target requirements and development directions & Concepts \\
\hline $\begin{array}{l}\text { For the elderly person who is attached to products they already own, people who would } \\
\text { love to drive their bike but started feeling that it does not serve their special needs of } \\
\text { handling anymore, people who avoid high investments } \\
\text { - Develop a product that improves the functional requirements mentioned above } \\
\text { through a modular system, which is adaptable to different types of standard } \\
\text { bicycles }\end{array}$ & Modular device \\
\hline $\begin{array}{l}\text { For the elderly person who feels the need for buying a new product with special } \\
\text { features for the elderly, but prefers that these features are hidden in a standard design, } \\
\text { for elderly people who do not want to be perceived as old } \\
\text { - Develop a product that improves the frame and other bike parts regarding the } \\
\text { functional requirements mentioned above and looks very similar to a standard } \\
\text { bike }\end{array}$ & $\begin{array}{l}\text { Special features in a } \\
\text { common bike look }\end{array}$ \\
\hline $\begin{array}{l}\text { For the elderly person who feels the need to buy a new product, which they perceive as } \\
\text { fulfilling their demands with respect to certain characteristics, such as stability, they } \\
\text { will only use the bicycle if they can already perceive these characteristics through the } \\
\text { product design } \\
\text { - Develop a completely new design for a senior bike addressing the special needs } \\
\text { of the elderly regarding the functional requirements mentioned above }\end{array}$ & $\begin{array}{l}\text { Realising key } \\
\text { properties via new } \\
\text { product design }\end{array}$ \\
\hline $\begin{array}{l}\text { For the elderly but as well as for other family members, if the family wants to buy a } \\
\text { new bike that addresses special needs for the elderly, for the elderly person who does } \\
\text { not have daily routines that make them use their bike very often, for other family } \\
\text { members who wants to buy a bike for their old relatives } \\
\text { - Develop a product-service-system, by which customized bike variants can be } \\
\text { obtained for different usage purposes by fulfilling the above functional } \\
\text { requirements }\end{array}$ & Multi-user bike \\
\hline $\begin{array}{l}\text { For the elderly person who loves to customize things by themselves, for the elderly } \\
\text { who are very engaged and interested in the biking sector, who are quite young but want } \\
\text { to be prepared for the day their skills will decrease, for kind of lead users } \\
\text { - Develop a service instead of a product, for example through video tutorials } \\
\text { explaining how to modify one's own bicycle in order to increase the } \\
\text { aforementioned functional requirements, to raise awareness of the topic "cycling } \\
\text { in an advanced age" and to create a sense of satisfaction }\end{array}$ & $\begin{array}{l}\text { Do-it-yourself } \\
\text { solution }\end{array}$ \\
\hline
\end{tabular}

\subsection{User-driven concept development}

An important activity carried out in the early phases of development is the identification of customer needs: the extent to which users interact with the product and how critical these interactions have to be examined. From the analysis of the usage context, requirements are derived. The descriptions of the tasks, the environment and the users themselves must be interpreted in such a way that they can be formulated as product requirements. These requirements must be translated into the actual user interface. This is challenging for some reasons. While requirements are related to specific functions and parameters of the product, wishes are formulated qualitatively. The users' statements need to be interpreted by the designer. The practical knowledge of product developers as well as of the typical user is of great advantage; however, they can also lead to critical biases. Therefore, a validation with regard to the user's wishes is also required. The biggest challenge is to identify and describe potential needs adequately. This is difficult because users often cannot articulate their needs themselves in a way understandable for the designer (Kujala, 2003). In many circumstances, needs cannot be even expressed properly because users and customers just ask for what they can figure out by incrementally improving existing products (Kärkkäinen et al., 2001).

The extraction of latent user needs, although potentially valuable, is challenging (Schaffhausen and Kowalewski, 2015; Bacciotti et al., 2016). To overcome this challenge while designing a transportation solution for the elderly, the design team asked which further user information is essential for completing the design task: 
- What types of bikes do elderly people prefer?

- How many kilometres for day they are used to travelling on average?

- What types of objects do they bring with them usually, considering size, weight and other features?

- How much are they willing to pay for?

- What are the benefits they perceive valuable?

- Is there a common perception of safety and if so, what is it like?

- Is there a special need for feeling protected, what about the seating comfort and the chance of using the tricycle solution with bad weather?

- What about the aesthetical requirements and the emotional dimension of the product?

- What does the product evoke in terms of the lifestyle the object implies, the prestige it generates for the owner as a feeling of distinction and recognition?

Interactions with users in the early stages of development go beyond simple needs' identification. Studies have found the importance of having users closely involved in design and development. Frequent and intimate user involvement is important for improving product concept, as well as for fostering innovation capabilities and product market performances (Bosman, 2005; Veryzer and Borja de Mozota, 2005). The way user integration is carried out determines its actual impact and it has to suitably planned for the specific objectives. In the case at hand, the aim was to understand the general needs and concrete requirements for transport solutions as well as the basic attitude towards senior bikes and tricycles by examining the daily habits of the elderly.

\subsection{Participatory concept development}

The user is the expert with regard to their usage context. This leads to methodological requirements for the solution search, with which the user needs are to be placed at the centre of the analysis. However, even during the active participation, the user's opinion on the development task can be manipulated. Indeed, the designer decides the extent and goals of the participation predominantly and introduces the subject to be discussed. By doing so, the wording the designers use already frames users' thinking. It remains open to what extent this opinion forming affects the results of the development and evaluation of the product under consideration. Latent or tacit knowledge can hardly be accessed this way (Sanders, 2002). One possibility to get some information on these levels is to combine the thinking process with a concrete event or situation in people's life (Nicolini, 2017).

\subsubsection{Research methodology}

In order to neither just let the elderly people evaluate the designers' ideas nor frame their own thinking in any direction, the decision for an exploratory, qualitative research design was made. The user study consists of two parts: an open focus group discussion on the subject of elderly's cycling habits and a qualitative evaluation of already existing market solutions. It took place in the day care centre "Altenund Service-Zentrum München (ASZ)" for elderly people, which is located the centre of Munich, Germany. This selection reflects the boundaries given by the development task. The ASZ offers a dining room and a catering service not only to help the elderly who are no longer able to do the cooking themselves but also to prevent them from always eating alone. This room was provided for the focus group discussion in an informal and, for the participants, well-known atmosphere. Ten elderly people took part in the task by the principle of self-selection (see Table 2). The discussions were recorded with permission and transcribed literally for further analysis.

There has to be a clear distinction between the levels of attitude and behaviour. In light of this, the main category to be addressed in the focus group discussion is not the transportation solution to be developed but rather the driving habits of elderly people. In order to understand not only what people think about the subject (attitude), but also what they are actually doing (behaviour), their previous driving behaviour must be understood as a coping strategy to meet their mobility needs. Therefore, these strategies shall be investigated and used as starting point for the development of product solutions with a high probability of use. The starting point was made with the question: Why did you decide to participate in this discussion round? The participants were encouraged to tell whatever they had in mind, their latest 
experiences as well as oldest memories irrespective of their being good or bad cyclists. Following this approach, the elderly themselves chose the topics to be discussed. Consequently, the topics chosen during the discussion indicate special relevance to the subject of mobility and transportation solutions and, therefore, offer insights into product requirements. This open approach provides more information than direct questions do, because these are too restrictive.

Table 2. Participant list focus group discussion

\begin{tabular}{|l|l|l|l|}
\hline Age & Sex & Cycling habits & Usage scenarios \\
\hline 88 & F & not cycling anymore & $\begin{array}{l}\text { used a ladies' bike for leisure reasons, today she is using a walker } \\
\text { frame }\end{array}$ \\
\hline 88 & M & not cycling anymore & $\begin{array}{l}\text { For doing sport, 2 years ago he stopped after falling from his racing } \\
\text { bicycle }\end{array}$ \\
\hline 78 & M & not cycling anymore & stopped cycling already 30 years ago \\
\hline 82 & M & not cycling anymore & $\begin{array}{l}\text { leisure reasons, mountain biking, stopped after wife's accident } 5 \text { years } \\
\text { ago }\end{array}$ \\
\hline 81 & F & not cycling anymore & loved biking for leisure, after diseases she started using a tricycle \\
\hline 79 & F & not cycling anymore & $\begin{array}{l}\text { to overcome distances in rural parts, stopped after moving into the city } \\
\text { centre 10 years ago }\end{array}$ \\
\hline 76 & F & actively cycling & uses E-bike for leisure and sport reasons \\
\hline 78 & M & actively cycling & uses E-bike for leisure and sport reasons \\
\hline 68 & M & actively cycling & $\begin{array}{l}\text { short and average distances, daily shopping, uses standard trekking } \\
\text { bike }\end{array}$ \\
\hline 74 & M & actively cycling & $\begin{array}{l}\text { short and average distances, uses trekking/city bike with lower } \\
\text { crossbeam }\end{array}$ \\
\hline
\end{tabular}

The second part of the interviews was an evaluation of existing transportation solutions. Functions were derived from the stories told, based on which the participants were asked to rate images of products that had already been distributed in the market regarding their perceived stability, comfort, attraction, storage needs and their own usage intention. Afterwards, all five criteria were ranked. The participants were asked to verbalize and describe the feelings and thoughts that led to their ranking results. The best-rated product should serve as a starting point for the product design. In the course of this process, the design team could validate their first requirements list and idea generation (see Table 1).

\subsubsection{Elderly lifestyle and problems}

The participants use or used to use any kind of bikes for several non-functional reasons, while the tricycle was used just to overcome functional mobility problems (see Table 2). All participants encouraged the development of senior bikes because they agree that cycling keeps the elderly fit.

They confirmed possible benefits in general, but not explicitly as an option for themselves. Accordingly, they were not very well informed about the available options. This refers to the statement that, as long as they feel safe on their own bike, they do not even think of adding a third wheel. However, having „, 3 wheels" was mentioned as a main feature. It turned out that a new product has to be with two rear wheels. Interestingly, even while discussing a three-wheel solution, they used the term "bicycle". The weight of the bike was mentioned as important, not only for holding and sliding, but also for the overall driving experience. The participants are used to have their own bikes or to borrow them on vacation (often ebikes). As long as they used to live in their own houses, they kept their bikes in the garage or the garden. New housing estates mostly do not offer enough parking space, but a regular bike size is perceived as manageable to store. The experience that one has to stop cycling for health issues was described as painful and results in an avoidance behaviour: once they have stopped, the overall usage motivation gets lost. Several reasons for quitting were discussed:

- It was more difficult to concentrate over a longer time period;

- It gets physically more demanding;

- The fear of heavy traffic; 
- One lady told that she bought a really expensive tricycle but even that did not save her from pain, so she used it for a short while until her health got worse and worse;

- They are afraid of getting hurt by an accident after a family member or friend had one;

- The spouse has stopped cycling for health issues.

The decision to stop cycling seems irreversible. Other usage barriers are:

- The fact that one needs to be trained in the handling of new bike options;

- Health restrictions are too strong and the participants do not take preventive measures;

- Lack of experience in the circle of family and friends, which are important influencers;

- The pricing is perceived as high (because they do not know if it brings the same joy as cycling as it used to be when they were younger, they do not know if the price is worthwhile).

During the group discussion, it became clear that friends and families are important influencers on purchasing decisions. In combination with the strong need for possibilities for trying and training, this leads to the conclusion that from the user's perspective, trustful relationships are a main requirement too. Furthermore, the elderly people want to stay actively engaged in all social fields. Although, on the one hand, they stressed their declining physical strength, on the other hand, they emphasized that they are taking on various voluntary activities in which they are not restricted by their physical condition. They want to be involved and not just limited to their deficits. Table 3 summarizes what exposed above.

Table 3. Bicycle wishlist

\begin{tabular}{|l|l|l|}
\hline Needs/functionalities & Main requirements & Specifications/solutions \\
\hline safety & stability & 3 big wheels, riding experience as usual, lights, brakes \\
\hline comfort & ergonomics & power assistance, low rise, soft seat, backrest \\
\hline attraction & bike look & perception of weight, 2 rear wheels, big wheels, bag \\
\hline storing & locking & bike-sized \\
\hline familiarity & trust relations & personal contact, service, trial options, design as usual \\
\hline activity & social integration & competence retention, participation, affordability \\
\hline
\end{tabular}

While the first four needs primarily target functionality and the design team attempted to translate them into technical requirements and possible solutions, the last two needs extend the range of solutions to include a social dimension. Furthermore, it appeared that these are dominant in the life of the elderly. If they are not addressed adequately because design has focused only on technical solutions, the resulting products are likely to fail.

\section{Solution development}

After identifying different dimensions of needs, it was questioned how they can be addressed in order to get a satisfying solution for the costumer. It became obvious that this should consider more than just a technical product. Moreover, given the diverse priorities and habits experienced by the participating elderly, developing only one solution was considered as unworkable. To ensure this adaptability, the design team discussed a modular solution (Fricke and Schulz, 2005).

Based on the information gathered, each member of the design team conceptualized up to two solutions. All of these solutions were again evaluated by each individual team member. After weighting, the design team decided to develop a tricycle kit, which consists of different add-ons and can be adapted to the bicycles the elderly already own (or new ones they can buy according to their individual preferences). The focus group discussion revealed that these preferences could be very different: some elderly people prefer a handlebar shaped in a certain way, others prefer a special frame shape. Most of the elderly people interviewed were not willing to pay a large sum of money for a new bicycle, they considered it unnecessary to buy "a new bike for an old person". Moreover, they want to keep the bicycles they are used to. These social and behavioural characteristics led the design team to the idea of developing a tricycle kit as solution to address these problems, which enables to fulfil the previously exposed technical requirements. If the kit will be sold separately and mounted to an already exiting bike, it is much cheaper than a completely new bike. If the kit will be sold together with a frame (that can be 
reused without the kit in the future, too), this allows the buyers to select colours, forms, etc. In addition, the designed kit is foldable, so the final dimensions do not differ substantially from a common bicycle when the transportation solution is parked. With the aim to account for both technological and economic feasibility, major efforts have concerned in order to develop:

- a compact technical system to be inserted in the seat commonly dedicated to the rear wheel,

- a transmission system whose functioning is not compromised by the foldability of the kit,

- a folding system with one degree of freedom to be operated easily.

As a result of the above design issues, the designed kit includes a rear hub and a rear motor, a battery, a carrying case, an ergonomic saddle, two wheels, a breaking system, a pinion for the chain connection with the pedals and a folding mechanism, as shown in Figure 1. During the summer school project, the proposed solution should be developed up to the embodiment design phase. In this phase, taking into account the lower speeds the elderly can achieve and similar functioning tricycles in the market, the design team did not perform a dynamic analysis in order to validate the functioning of the solution.
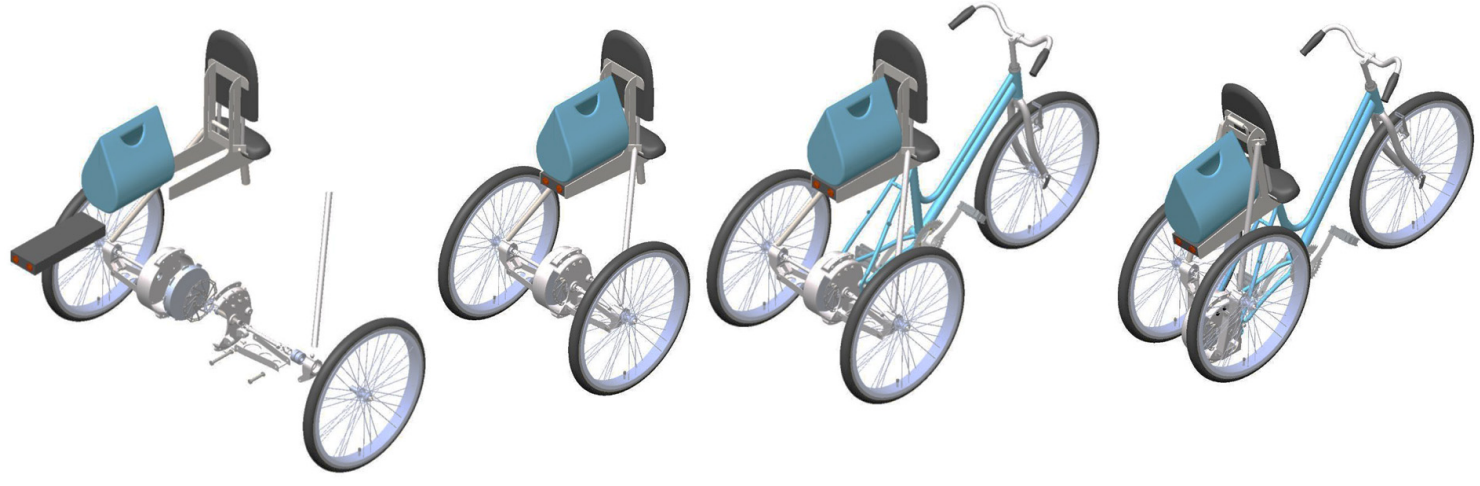

Figure 1. Foldable tricycle kit

Contrary to the current trend of selling new bicycle concepts over the Internet in order to save costs and reduce entrepreneurial risks, the final product concept to be realized sees personal contact as a core characteristic. This is enabled by the opening of a concept store, which can be seen as the solution to non-technical issues. This concept store serves as a day café, informal meeting place, showroom and workshop. The idea behind this is, on the one hand, the empowerment of older people by enabling them to operate this concept store in large autonomy by taking over volunteering jobs in the long term. On the other hand, the older people can be involved in the concept store to network, advertise and further develop the technical product, to promote its distribution.

The solution chosen to answer the development task is supposed to offer a holistic user experience. The underlying business model is based on two approaches:

1. Marketing a social target groups with a technical solution;

2. Empowering a social target groups by offering a non-technical solution.

The empowerment of the target group not only contributes to the fact that they play a decisive role themselves in the entire product lifecycle in the long term and that product acceptance is therefore generally high. The general strengthening of the elderly also means preserving social skills such as curiosity, general interest and the tendency to get involved in new things and a high level of activity, which in turn increases the demand for the technical solution (Pelizäus-Hoffmeister, 2013).

With reference to the elderly, it can be said that the final solution does meet all the important requirements. The elderly people who have taken part in the user study were asked to evaluate the solution after the concept was virtually prototyped and explained. Overall and in all respects, the evaluation was more positive than for the existing models presented during the focus group discussion. According to the feedback, the greatest improvement was achieved with regard to the intention of use. Here, of course, it must be acknowledged that a declaration of intent tends to be explanatory at the attitude level and allows only poorly valid statements to be made at the behavioural level. Therefore, the reported advantages must be empirically verified in another follow-up project. 


\section{Conclusion}

The paper presents a case study that involves participatory and human-centred design. It is shown how knowledge of the impact of social aspects might affect the development of technical systems and particularly on requirements elicitation and management. The starting point was the social need for keeping the growing elderly population mobile. This design task was dealt with through a holistic approach. It turned out that the definition of requirements for technical assistance systems for the elderly should include a systematic and sensitive examination of daily practices in which the assistance systems are to be deployed. Considerations on how technical functionalities can be used to overcome performance limitations are just one side of the coin: the context of use and the human life and action situation are decisive for product acceptance and these individual motives for action and values have to be disclosed. If it is not known why someone uses something, a technical product can hardly address this need. Non-functional needs seem to play a decisive role, especially for the elderly. This calls the attention on the benefit of participatory practices, not just in a social perspective, but also from the viewpoint of designing successful products.

During the product development task, a multidisciplinary team had multiple assignments on which they had to collaborate. It clearly emerged that different backgrounds give rise to different points of view on a specific situation. This is critical for considering the product from both engineering and non-technical perspectives. It is strongly believed that the overall team performance was improved by putting the different competencies of its participants together; this is fostered, for instance, by an appropriate subdivision of tasks, as well as complementing different working styles and expertise. With respect to faced challenges, one of the hardest aspects was about management tasks. Another challenge regards the fact that the members prefer different media and software, because of the cultural and professional differences. Therefore, it could be worth for collaboration teams investing enough energy in finding an integrated platform, where all the management and design tools can be found in one place.

Naturally, each design step can be supported by plenty of methods and to find the most appropriate one is critical. The main outcome of this project is that the participatory design approach provided the most usable and insightful information. During the design process, the design team also paid attention to ergonomic principles and methods. However, it turned out that the focus on effectiveness, efficiency and usability in the context of product development is not sufficient to meet user needs adequately in product design. In particular, the non-functional needs reported by the participants led to the development of the final product solution. From the perspective of the elderly, the adaptability of the developed solution to already existing products offers a great advantage. Because the kit can be used with a standard bicycle, the elders do not have to first train the handling of a new product. Rather, they can get their usual enjoyment of cycling. Furthermore, the purchase cost is not only absolute, but also relationally lower, because a bike purchased with the kit can be used even without it: thus, the elderly can share a bike with their partner, friends or even grandchildren. As demonstrated in the course of the investigation, a key reason for riding bicycles in old age is securing social participation. This can be supported on several levels with the solution developed here. Especially when products are to be developed for a sensitive target group, it is therefore advisable to actively involve those in the development process so that one can properly understand and address their usage motives. Of course, not all requirements are equally satisfied within the solution and it has to be emphasized that the statements of this study are limited due to the small sample size. For reliable results, the study should be extended considerably. Nevertheless, valuable insights can be derived for further development projects, especially in the field of design for the aging population.

\section{Acknowledgment}

The development project analysed in this contribution was carried out in context of the ipdISS17. Many thanks to all participants and especially the ASZ München for providing an environment in which trusting and open discussions were possible.

\section{References}

Andreasen, M.M. and Hein, L. (1987), Integrated Product Development, Springer, Heidelberg. 
Bacciotti, D., Borgianni, Y., Cascini, G. and Rotini, F. (2016), "Product Planning techniques: investigating the differences between research trajectories and industry expectations", Research in Engineering Design, Vol. 27 No. 4, pp. 367-389. https://doi.org/10.1007/s00163-016-0223-6

Backes, G. and Clemens, W. (1998), Lebensphase Alter - Eine Einführung in die sozialwissenschaftliche Altersforschung, Juventaverlag, Weinheim.

Barki, H. and Hartwick, J. (1989), "Rethinking the Concept of User Involvement", MIS Quarterly, Vol. 13 No. 1 , pp. 53-63. https://doi.org/10.2307/248700

Biermann, H. and Weißmantel, H. (2003), Der SENSI-Katalog: Benutzerfreundliches und seniorengerechtes Design. [online] TU Darmstadt. Available at: http://www.emk.tu-darmstadt.de/ weissmantel/sensi/sensi.html (accessed 16.11.2017).

Birken, T., Pelizäus-Hoffmeister, H. and Schweiger, P. (2016), "Judging the Desirability and Acceptance of Assistance Systems for the Elderly - Lessons Learned with a Fieldwork Approach", Proceedings of the 49th Annual Hawaii International Conference on System Sciences HICSS, January 5-8, 2016, IEEE Computer Society, pp. 579-588. https://doi.org/10.1109/HICSS.2016.78

Bosman, Y.M. (2005), "Measuring the user participation construct", 3rd Twente Student Conference on IT, Enschede, June 2005.

Clarkson, P.J., Coleman, R., Keates, S. and Lebbon, C. (2013), Inclusive design: Design for the whole population, Springer-Verlag, London.

Clemens, W. (2004), "Lebenslage und Lebensführung im Alter - zwei Seiten einer Medaille? ", In: Backes, G.M., Clemens, W. and Künemund, H. (Eds.), Lebensformen und Lebensführung im Alter, Springer VS, Wiesbaden, pp. 43-58. https://doi.org/10.1007/978-3-663-10615-9_3

Connell, B.R., Jones, M., Mace, R., Mueller, J., Mullick, A. et al. (1997), The Principles of Universal Design. [online] North Carolina State Aniversity. Available at: https://projects.ncsu.edu/design/cud/about_ud/udprinciplestext.htm

Damodaran, L. (1996), "User involvement in the systems design process - a practical guide for users", Behaviour \& Information Technology, Vol. 15 No. 6, pp. 363-377. https://doi.org/10.1080/014492996120049

DIN ISO (2010), ISO 9241-210:2010 Ergonomics of human-system interaction - Part 210: Human-centred design for interactive systems, Beuth Verlag GmbH.

Eisma, R., Dickinson, A., Goodman, J., Syme, A., Tiwari, L. and Newell, A.F. (2004), "Early user involvement in the development of information technology-related products for older people", Universal Access in the Information Society, Vol. 3 No. 2, pp. 131-140. https://doi.org/10.1007/s10209-004-0092-z

Essén, A. and Östlund, B. (2011), "Laggards as innovators? Old users as designers of new services \& service systems", International Journal of Design, Vol. 5 No. 3, pp. 89-98.

Fricke, E. and Schulz, A.P. (2005), "Design for Changeability (DfC): Principles to enable changes in systems throughout their entire lifecycle", Systems Engineering, Vol. 8 No. 4, pp. 342-359. https://doi.org/10.1002/sys.20039

Hassenzahl, M., (2008), "User Experience (UX): Towards an experiential perspective on product quality", 20th Conference on l' Interaction Homme-Machine, Metz, France, September 02-05, 2008, ACM New York, pp. 11-15. https://doi.org/10.1145/1512714.1512717

Kärkkäinen, H., Piippo, P., Puumalainen, K. and Tuominen, M. (2001), “Assessment of hidden and future customer needs in Finnish business-to-business companies”, R\&D Management, Vol. 31 No. 4, pp. 391-407. https://doi.org/10.1111/1467-9310.00227

Kujala, S. (2003), "User involvement: a review of the benefits and challenges", Behaviour \& Information Technology, Vol. 22 No. 1, pp. 1-16. https://doi.org/10.1080/01449290301782

Lee, C., Myrick, R., Asai, D., Coughlin, J.F. and De Weck, O.L. (2013), "Learning from a design experience: Continuous user involvement in development of aging-in-place solution for older adults", Proceedings of ICED'13 / the 19th International Conference on Engineering Design, Seoul, Korea, August 19-22, 2013, The Design Society, Glasgow.

Limbourg, M. and Matern, S. (2009), Erleben, Verhalten und Sicherheit älterer Menschen im Straßenverkehr, Mobilität und Alter, Band 04, Schriftenreihe der Eugen-Otto-Butz-Stiftung, Köln.

Mollenkopf, H. and Flaschenträger, P. (2001), Erhaltung von Mobilität im Alter - Endbericht des vom Bundesministerium für Familie, Senioren, Frauen und Jugend (BMFSFJ) geförderten und unter Leitung von Prof. Dr. Wolfgang Zapf am Wissenschaftszentrum Berlin für Sozialforschung (WZB) durchgeführten Projektes, Kohlhammer, Stuttgart.

Mottschall, M. (2012), PROSA Fahrräder: Entwicklung der Vergabekriterien für ein klimaschutzbezogenes Umweltzeichen. [online] Öko-Institut e.V. Available at: https://www.oeko.de/oekodoc/1720/2012-341-de.pdf (accessed 14.12.2017). 
Nicolini D. (2017), "Practice Theory as a Package of Theory, Method and Vocabulary: Affordances and Limitations", In: Jonas M., Littig B. and Wroblewski A. (Eds.), Methodological Reflections on Practice Oriented Theories, Springer, Cham, pp. 19-34. https://doi.org/10.1007/978-3-319-52897-7_2

Niemelä-Nyrhinen, J. (2007), "Baby boom consumers and technology: shooting down stereotypes", Journal of Consumer Marketing, Vol. 24 No. 5, pp. 305-312. https://doi.org/10.1108/07363760710773120

Ottosson, S. and Sterten, J. (2014), "User Participation is not always an easy thing when developing an Innovation", Proceedings of the DESIGN 2014 /13th International Design Conference, Dubrovnik, Croatia, May 19-22, The Design Society, Glasgow, pp. 579-588.

Paetzold, K. and Wartzack, S. (2012), "Challenges in the Design of Products for Elderly People", 9th International Workshop on Integrated Product Development, IPD Workshop, Magdeburg, 2012.

Pelizäus-Hoffmeister, H. (2013), Zur Bedeutung von Technik im Alltag Älterer: Theorie und Empirie aus soziologischer Perspektive, Springer VS, Wiesbaden.

Preiser, W.F.E. and Smith, K.H. (2011), Universal Design Handbook, 2nd ed., McGraw-Hill, New York.

Pucillo, F., Becattini, N. and Cascini, G. (2016), "A UX Model for the Communication of Experience Affordances", Design Issues of MIT Press Journal, Vol. 32 No. 2, pp. 3-18. https://doi.org/10.1162/DESI_a_00378

Rieuf, V., Bouchard, C. and Aoussat, A. (2015), "Immersive moodboards, a comparative study of industrial design inspiration material", Journal of Design Research, Vol. 13 No. 1, pp. 78-106. https://doi.org/10.1504/JDR.2015.067233

Sanders, E.B.N. (2002), "From user-centered to participatory design approaches", In: Frascara, J. (Ed.), Design and the Social Sciences: Making Connections, Taylor \& Francis, London, pp. 1-7.

Schaffhausen, C.R. and Kowalewski, T.M. (2015), "Large-scale needfinding: methods of increasing usergenerated needs from large populations", Journal of Mechanical Design, Vol. 137 No. 7. https://doi.org/10.1115/1.4030161

Seidel, D., Brayne, C. and Jagger, C. (2011), "Limitations in physical functioning among older people as a predictor of subsequent disability in instrumental activities of daily living", Oxford Journals Age and Ageing, Vol. 40 No. 4, pp. 463-469. https://doi.org/10.1093/ageing/afr054

United Nations (2013), World Population Aging 2013. [online] DESA. Available at: http://www.un.org/en/ development/desa/population/publications/pdf/ageing/WorldPopulationAgeing2013.pdf_ (accessed 20.11.2017).

Vajna, S. (2014), Integrated Design Engineering: Ein interdisziplinäres Modell für die ganzheitliche Produktentwicklung, Springer Vieweg, Berlin/Heidelberg.

Veryzer, R.W. and Borja de Mozota, B. (2005), "The Impact of User-Oriented Design on New Product Development: An Examination of Fundamental Relationships", The Journal of Product Innovation Management, Vol. 22 No. 2, pp. 128-143. https://doi.org/10.1111/j.0737-6782.2005.00110.x

Walter, J., Paetzold, K. and Nitsch, V. (2015), "Description of a competence oriented approach for designing technical assistance systems”, Proceedings of ICED'15 / the 20th International Conference on Engineering Design, Milan, Italy, July 27-30, 2015, The Design Society, Glasgow, 2015, pp. 2220-4334.

Wilkinson, C.R. and De Angeli, A. (2014), "Applying user centred and participatory design approaches to commercial product development", Design Studies, Vol. 35 No. 6, pp. 614-631. https://doi.org/10.1016/j.destud.2014. 06.001

Anne Wallisch, Dipl.-Soz., M.A.

Bundeswehr University Munich, Institute for Technical Product Development

Werner-Heisenberg-Weg 39, 85577 Neubiberg, Germany

Email: anne.wallisch@unibw.de 